the ethmoid can be reached effectively. If the operation is undertaken with the patient lying on the operating table, where the shock is very much diminished, it is usually feasible to correct the septum and complete the operation on the labyrinth at one sitting. The other suggestion by Dr. Welty, that the relief accomplished by an intranasal operation on the accessory sinuses can be got just as well from simple irrigation, I am not willing to accept. I would be almost willing to take the stand that any accessory sinus condition which can be cured by irrigation will get well spontaneously if left alone, with only the usual application of epinephrin or cocain applied under the middle turbinated body to facilitate temporary drainage. It is only, as a rule, the chronic form of accessory sinus disease where an operation is called for, and in these cases irrigation alone is usually of very little value.

Dr. Samuel Igrauer, Cincinnati: I have not tried the method Dr. Clift mentioned, although I found some reference to it in the literature. The objection stated in the literature is that the patient cannot control the soft palate and possibly not the tongue while the picture is being taken and therefore there is some danger of the film being moved during the exposure. This difficulty may, perhaps, be overcome by cocain or by a rapid roentgenogram. The film in the mouth method was suggested by Scheier some years ago but nothing seemed to come of it. If this method proves successful it will be better than the method I presented this morning. If it is not successful the oblique method will remain the best. Dr. Beck is inclined to question the value of the latter method. If he will look at the plates perhaps he will change his mind since it is difficult to show details in lantern slides. I am convinced that one can tell whether the anterior or posterior group of cells is involved. I think that is valuable. There is one trouble with a patient who has recovered from an ethmoiditis or sphenoiditis, that the recovered cells may still show pathologically on the roentgenogram, so that one must consider the patient's history and the clinical findings in connection with the plate. I do not pretend to say that one should rely on the roentgenogram plate entirely; one certainly must employ clinical methods, but by combining the two fewer mistakes will be made.

\section{THE QUANTITATIVE RELATIONSHIP OF MILK-BORNE INFECTION IN THE TRANSMISSION OF HUMAN COMMUNICABLE DIS- EASES *}

EUGENE R. KELLEY, M.D. BOSTON

For practical public health administrative purposes the list of human communicable milk-borne diseases that are of importance in the United States may be reduced to five: diphtheria, scarlet fever, septic sore throat, tuberculosis and typhoid fever. The only other group of human diseases which have certain definite claims for admission to this group of communicable diseases are the so-called infantile diarrheas. The entire question of the specificity of the micro-organisms that produce infantile diarrheas and of the part that milk may play in the transmission of such micro-organisms is still so far from definitely settled that it is probably wiser, in considering the relationship of milk-borne infection to human diseases, to limit its consideration to the diseases first enumerated.

In recent years there has been a great deal of agitation relative to the comparative importance of milk infection in the transmission of human diseases.

* Read before the Section on Preventive Medicine and Public Health at the Sixty-Seventh Annual Session of the American Medical Association, Detroit, June, 1916.
Whenever the subject is approached in an impartial manner, it is rather astonishing to see how little real basis there is on which to form any definite estimates as to the quantitative importance of milk infection as compared to other modes of infection, such as water, carriers, or direct contact.

Of the five human diseases to be considered, it may be seen at once that tuberculosis represents a distinct problem. The evidence that incriminates cow's milk as a factor in the transmission of tuberculosis to human beings is now quite conclusive. Nevertheless, the data on which are based our quantitative estimates of the prevalence of human tuberculosis of bovine origin are comparatively scanty. This is because of the inherent difficulty in determining in any given case or cases whether or not it is the human or bovine type of the tubercle bacillus that is fundamentally responsible for the disease process. Such researches as those of the British Royal Commission and of the health department of New York City prove that the bovine tubercle bacillus is of frequent occurrence under conditions which render it practically impossible to come to any other conclusion than that the bovine tubercle bacillus is the fundamental cause of the disease process in a wide variety of human tuberculous lesions, especially in children. From these investigations, Park and Krumwiede of the New York City health department concluded that at least one third of all cases of tuberculosis in children under 5 years of age, as the disease occurred in New York City, were due to infection with the bovine tubercle bacillus and only a slightly less proportion in the cases occurring between 5 and 15 years of age.

The methods that must be employed to demonstrate whether or not it is the bovine or human type of bacillus that is at fault in any given case of tuberculosis are so intricate and involved that it does not seem likely at present that we shall soon have any accurate method of demonstrating the true frequency of bovine tuberculous infection. We will thus rest content with the general assumption that a considerable proportion of the cases of human tuberculosis are in all probability due to infection transmitted from the cow through drinking raw cow's milk.

With tuberculosis left at one side, the question of the relationship of infected milk to the transmission of disease in cases of the other four diseases, diphtheria, scarlet fever, septic sore throat and typhoid fever, ought to be a very much easier point to determine. Careful and thoroughgoing adherence to the laws of epidemiology, supplemented by equally careful and well coordinated laboratory investigations, will in the great majority of instances, in the case of epidemics, prove conclusively whether or not given cases of these diseases may be fairly attributed to milk infection. Nevertheless, at the present time there are apparently very few health departments in the United States that do determine, with even a very rough degree of accuracy, whether or not given outbreaks of disease are due to milk infection. In many instances outbreaks are very evidently alleged to be due to milk infection without any scientific investigations being carried out to verify or disprove this hypothesis.

There are several reasons why it is impossible in most instances to say whether or not milk could reasonably be held to be the channel of infection. It is the exception rather than the rule that any attempt is made to determine the probable source of infection as a routine procedure. 
Even if physicians or health officials make an attempt to determine the always possible culpability of milk, they usually carry out the investigation no farther than to establish a suspicious frequency of infection in persons having a, common milk supply. Then the outbreak is promptly labeled a milk epidemic and cverybody is satisfied with the explanation except the milk man. He, having nothing at stake except perhaps the savings of a life time and a business reputation built up by years of earnest effort, timidly protests against such a harsh and hasty judgment, but his protests are brushed to one side by the cocksure doctor or health board that has condemned him and his products on most incomplete circumstantial evidence alone. Time and again careful epidemiologic investigation has shown that an outbreak that at first appeared to be milk borne has proved to be carrier borne or water borne, and vice versa.

The practical conclusion to be drawn from these facts of common knowledge to sanitarians is that an outbreak of disease may be considered tentatively as probably milk borne on a showing of high frequency of cases on a common milk route or on routes having a common source of supply. This alone is ample evidence to demand prompt administrative action, such as shutting off the supply, or, better, careful pasteurization, an investigation of dairies producing milk and of middlemen handling milk in order to detect the possible source, and such other similar precautionary measures as circumstances may suggest. In order definitely to declare any disease milk borne, however, it is necessary to carry out, by epidemiologic and laboratory means, a careful search for and detection of the disease, or a past history of the disease, in a person or the persons handling the milk at any point, and a thoroughgoing exclusion of all other probable channels of infection. When this perfectly fair and reasonable system of checking is applied to alleged milk-borne epidemics, it is surprising to note how often such epidemics fail to show any clear-cut proof of being milk borne.

Even definite proof of milk being the channel of infection in epidemics may not fairly indicate the total relative importance of milk as a channel of disease transmission.

Although at the present time no definite epidemiologic standards exist as to what is meant by the terms "outbreak" or "epidemic," yet analyses of morbidity reports will nearly always show that for the diseases under consideration, one, septic sore throat, is reported almost exclusively in epidemics. In the case of diphtheria, scarlet fever or typhoid, their sporadic or endemic occurrence far outweighs, in the aggregate, their occurrence in epidemics. It is almost unique to have a single or sporadic case of any of these diseases definitely traced to milk infection. It is easy enough to assume that many such cases must be due to infected milk, but to prove it, even to render the case fairly reasonable against milk, is another matter.

A tabulation of investigations of outbreaks and epidemics carried out over a series of five years by the field force of the Massachusetts State Board of Health from 1910 to 1914, inclusive, shows that 240 epidemics and outbreaks of diphtheria, scarlet fever, septic sore throat and typhoid, due to. all causes, were investigated. The total number of cases recorded is 3,198 , but in many instances a statement is made that the true number of cases is believed to be greater, or that more cases may yet occur subsequent to the report. Because of the policy followed, it is believed that practically every outbreak of any material dimensions of these particular diseases occurring in the state was investigated.

Even assuming for purposes of argument that the admitted incompleteness of cases is as great as 50 per cent., a most liberal concession, this would only assign about 6,000 cases of these diseases to epidemics or outbreaks.

In the same years a grand total of 85,958 cases of these same diseases were officially reported in the state, and this would indicate that the almost unnoticed sporadic or endemic prevalence of these diseases is a vastly greater problem than their occasional epidemic occurrence. No evidence is available pointing to milk infection in any of these sporadic cases. The compari-

\begin{tabular}{|c|c|c|c|c|}
\hline Year & $\begin{array}{c}\text { Number } \\
\text { of } \\
\text { Epidemics }\end{array}$ & $\begin{array}{l}\text { Number } \\
\text { Due to } \\
\text { Milk }\end{array}$ & $\begin{array}{c}\text { Number Due } \\
\text { to Other } \\
\text { Causes }\end{array}$ & $\begin{array}{c}\text { Percentage } \\
\text { Milk } \\
\text { Borne }\end{array}$ \\
\hline $\begin{array}{r}\text { Diphtheria: } \\
1910 \\
1911 \\
1912 \\
1913 \\
1914\end{array}$ & $\begin{array}{r}4 \\
4 \\
13 \\
9 \\
9 \\
26\end{array}$ & $\begin{array}{l}0 \\
\mathbf{1} \\
\mathbf{1} \\
0 \\
0\end{array}$ & $\begin{array}{r}4 \\
12 \\
8 \\
9 \\
26\end{array}$ & $\begin{array}{c}0 \\
7.7 \\
11 \\
0 \\
0\end{array}$ \\
\hline Total & 61 & 2 & 59 & 3.2 \\
\hline $\begin{array}{c}\text { Septic sore throat: } \\
1910 \\
1911 \\
1912 \\
1913 \\
1914\end{array}$ & $\begin{array}{l}0 \\
1 \\
0 \\
3 \\
2\end{array}$ & $\begin{array}{l}0 \\
1 \\
0 \\
2 \\
1\end{array}$ & $\begin{array}{l}0 \\
0 \\
0 \\
1 \\
1\end{array}$ & $\begin{array}{r}0 \\
100 \\
0 \\
66 \\
50\end{array}$ \\
\hline Total & 6 & 4 & 2 & 66 \\
\hline $\begin{array}{c}\text { Scarlet fever: } \\
1910 \\
1911 \\
1912 \\
1913 \\
1914\end{array}$ & $\begin{array}{r}11 \\
10 \\
8 \\
23 \\
35\end{array}$ & $\begin{array}{r}\mathbf{1} \\
\mathbf{1} \\
\mathbf{2} \\
\mathbf{1} \\
2\end{array}$ & $\begin{array}{r}10 \\
9 \\
6 \\
22 \\
33\end{array}$ & $\begin{array}{c}9 \\
10 \\
25 \\
4.3 \\
6.0\end{array}$ \\
\hline Total & 87 & 7 & 80 & 8 \\
\hline $\begin{array}{c}\text { Typhoid fever: } \\
1910 \\
1911 \\
1912 \\
1913 \\
1914\end{array}$ & $\begin{array}{r}15 \\
11 \\
6 \\
31 \\
23\end{array}$ & $\begin{array}{r}10 \\
2 \\
3 \\
8 \\
10\end{array}$ & $\begin{array}{r}\mathbf{5} \\
9 \\
\mathbf{3} \\
2 \mathbf{3} \\
13\end{array}$ & $\begin{array}{l}66.6 \\
18.2 \\
60 \\
25.8 \\
43.5\end{array}$ \\
\hline Total & 86 & 33 & 53 & 38.4 \\
\hline Grand total & 240 & 46 & 194 & 19.2 \\
\hline
\end{tabular}

sons shown in Table 1 , based on the Massachusetts investigations, are of interest in this connection:

In Table 1 the incidence of more than one case in different families in the same locality at the same time is classed as an epidemic or an outbreak with the natural effect that with three or four exceptions the average number of cases per epidemic is small. There have been many small outbreaks in which no suspicion has been raised relative to the milk supply that have been handled wholly by local authorities and concerning which no epidemiologic information is recorded in the state department of health. This fact does not invalidate the significance of the table, because for several years past it has been the fixed policy of the department to investigate every case of contagious disease reported from a milk-producing farm, as well as every outbreak, whether in a large or small community, in which milk was at all under suspicion. Therefore a fuller table of outbreaks would only tend to lessen the percentage of milk borne. 
In the same connection it is interesting to note that in these five years fifty-five other investigations were made by the state heaith inspectors of Massachusetts in instances in which a single case of contagious disease was reported from a milk-producing farm, and precautions ordered and observed, with no secondary cases of any nature subsequently occurring.

As regards the occurrence of milk infection in sporadic or nonepidemic cases of these diseases, owing to the fact that Massachusetts local boards of health are required by law to report to the state health authorities only the names, addresses, diagnoses and dates on which cases of infectious diseases are reported to them and that the routine notifications to the state health department are limited strictly to this information, the routine records of cases in the Massachusetts state health department throw no light whatever on the question. During an investigation in 1915 of the entire question of milk in its relation to the public health, the Massachusetts state health department sought to supplement the lack of any routine information in its own records as to frequency of milk infection by requesting information on this point from all of the local boards of health in the state. Accordingly, a circular questionnaire was sent to the local boards of health in the commonwealth, 353 in all, asking for statements as to the total number of cases of typhoid fever, diphtheria, scarlet fever and septic sore throat reported to the local board of health during the five-year period, from 1909 to 1913; the number recorded as due to milk infection following investigation by the local board; the number suspected of being milk borne without conclusive evidence being obtained, and the total number of deaths from the same diseases in the corresponding period and the number of such deaths attributed to milk infection.

Forty towns, having an aggregate population of 50,134 , stated that no cases of these diseases due to any causes were reported in this period to their local boards of health. Inasmuch as these "no cases" towns are all comparatively small, it may be reasonably inferred that at least no outbreak of these diseases could have occurred in any of them during the period under inquiry, for such an occurrence would have been practically certain to have become a matter of record in the local board of health office. It is also true that in practically all of these towns, the machinery of milk production and distribution is extremely simple.

The remaining 102 towns and the thirty-four cities, total 136, answering the questionnaire represent an aggregate population of 2,703,759 (census of 1910), or 80 per cent. of the total population of the state. They reported as is shown in Table 2 .

Analysis of these totals demonstrates that in only 0.03 per cent. of cases was the transmission of diphtheria definitely assigned to infected milk, and in only 0.19 per cent. was milk either proved or suspected; 1.6 per cent. of the reported cases of scarlet fever were definitely attributed to milk infection, and 1.8 per cent. proved or suspected; in 79 per cent. of the cases of septic sore throat (not reportable in Massachusetts until 1914) milk was assigned as the cause; and in 5 per cent. of the cases of typhoid, milk was definitely assigned as the cause and in 6 per cent. of the cases of typhoid milk was either proved or suspected to be the agent of infection in this disease. Taking all of these diseases in a group, 3.9 per cent. were definitely attributed to milk, and in 4 per cent. of all the cases milk was proved or suspected. Considering mortality, 3 per cent. of typhoid deaths are possibly attributable to milk, 0.08 per cent. of diphtheria deaths, 0.8 per cent. of scarlet fever deaths, and 98 per cent. of septic sore throat deaths; an average for the whole group of 2 per cent. of the deaths may be attributed to infected milk.

TABLE 2.-NUMBER OF CASES AND DEATHS DUE TO MILK AND OTHER CAUSES

\begin{tabular}{|c|c|c|c|c|c|c|}
\hline Diseases & $\begin{array}{l}\text { Number } \\
\text { Cases, } \\
\text { 1909-1913 }\end{array}$ & $\begin{array}{l}\text { Number } \\
\text { Deaths, } \\
1909-1913\end{array}$ & $\begin{array}{c}\text { Number } \\
\text { Cases } \\
\text { Due } \\
\text { to } \\
\text { Milk }\end{array}$ & $\begin{array}{l}\text { No. } \\
\text { Deaths } \\
\text { Due } \\
\text { to } \\
\text { Milk }\end{array}$ & $\begin{array}{l}\text { No. } \\
\text { Cases } \\
\text { Milk } \\
\text { Sus- } \\
\text { pected* }\end{array}$ & $\begin{array}{l}\text { Deaths } \\
\text { Milk } \\
\text { Sus- } \\
\text { pected* }\end{array}$ \\
\hline $\begin{array}{l}\text { Typhoid fever...... } \\
\text { Diphtheria......... } \\
\text { Scarlet fever...... } \\
\text { Septic sore throat. }\end{array}$ & $\begin{array}{r}11,282 \\
31,866 \\
31,012 \\
2,436\end{array}$ & $\begin{array}{r}1,425 \\
2,580 \\
991 \\
49\end{array}$ & $\begin{array}{r}553 \\
11 \\
495 \\
1,914\end{array}$ & $\begin{array}{r}37 \\
1 \\
8 \\
48\end{array}$ & $\begin{array}{r}135 \\
49 \\
57 \\
0\end{array}$ & $\begin{array}{l}8 \\
1 \\
0 \\
0\end{array}$ \\
\hline Totals............ & 76,596 & 5,045 & 2,973 & 94 & 241 & 9 \\
\hline
\end{tabular}

* "Suspected" here means that milk was considered to be the probable source of infection, but the suspicion was not conclusively proved.

\section{CONCLUSIONS}

From this statistical study, although it is incomplete in several respects, many interesting and suggestive deductions can be made.

Analysis of Massachusetts investigations does not corroborate the statements to be found in various places in recent literature, alleging that milk is a very important channel of infection in a quantitative sense in this group of diseases.

Massachusetts experience would seem to indicate that even in raw milk supplies, with widely varying conditions of supervision, diphtheria transmission through milk is so rare an occurrence as to be negligible.

The transmission of scarlet fever through milk, while much more common than diphtheria, is of very small percentage significance.

Typhoid fever in this large series, extending over a period of years, was reasonably attributed to milk infection in a much larger number of cases than diphtheria or scarlet fever, but these amounted in all to only 5 per cent. of the total cases of typhoid reported, a very different story from the statements of from 10 to 25 per cent. frequency of typhoid infection by milk that can be found in various places in recent public health literature.

Septic sore throat is par excellence the milk-borne disease, but its occurrence is fortunately relatively rare. When it does occur, it is nearly always in epidemic form and is of more serious consequences.

In all probability, the menace of tuberculosis is the best justification that we have as practical sanitarians for the amount of propaganda that has been carried on and the money that has been expended by health authorities for the supervision and control of milk supplies, so far as such supervision aims at the suppression of communicable diseases.

Relation of Mental Deficiency to Delinquency.-The relation of mental deficiency to delinquency, dependence and immorality, is vastly more important in the years of adult life than in childhood, but the phases of the problem as they present themselves in the years of school life are more readily manageable. The school population, therefore, constitutes the larger group to which access for satisfactory investigation can be had.-Treadway, Public Health Reports, Nov. 24, 1916. 